\title{
Resúmenes de los trabajos de investigación de los alumnos del Primer Año de la Facultad de Estomato- logía, presentados en la feria científica del curso de investigación científica Il, como parte de su formación científica en la Carrera de Estomatología - UPCH
}

Castillo-Andamayo D¹, Del Castillo-López C², Pachas-Barrionuevo F³ . Rev Estomatol Herediana. 2012; $22(1): 68-73$.

${ }^{1}$ Coordinador del curso

${ }^{2}$ Jefe de Departamento

${ }^{3}$ Directora de la Carrera de Estomatología

Los resúmenes que se presentan a continuación corresponden a proyectos de investigación planteados dentro del curso de Investigación Científica II con Estudiantes del Primer Año de la Facultad de Estomatología Roberto Beltrán", contando con la participación de los ingresantes 2011- I y de Docentes de la Facultad de estomatología y la Facultad de Ciencias y Filosofía en calidad de Asesores de Investigación. Este curso se ha desarrollado con el propósito de cultivar la investigación en lo estudiantes desde los primeros años de Facultad, por lo cual la elaboración de proyectos de investigación de carácter multidisciplinario permiten al estudiante relacionar conceptos de ciencias básicas aplicadas a la Estomatología.

Estilos de aprendizaje en alumnos de primer y segundo año de la facultad de estomatología de la Universidad Peruana Cayetano Heredia 2011.

Aldazábal K ${ }^{1}$, Cabezas $\mathrm{M}^{1}$, Cruz Aํㅗㄹ Hernández $\mathrm{K}^{1}$, Márquez I ${ }^{1}$, Villavicencio $\mathrm{E}^{2}$.

${ }^{1}$ Alumno de Primer Año de la Facultad de Estomatología Universidad Peruana Cayetano Heredia. Lima, Perú.

${ }^{2}$ Facultad de Estomatología Universidad Peruana Cayetano Heredia. Lima, Perú.

El aprendizaje es entender y captar información de la naturaleza y del medio que nos rodea, los estilos de aprendizaje se refieren al hecho de cómo cada persona utiliza su propio método o estrategia para aprender. La manera en que cada persona aprende, tiene que ver con la forma en que estructura los contenidos, forma y utiliza conceptos, interpreta la información, selecciona medios de representación, y sobre todo cómo resuelve los problemas. La clasificación de estilos de aprendizaje que utiliza el test CHAEA, coincide con el inventario de Kolb, que evalúa dos dimensiones principales, una que profundiza en la forma cómo se percibe la nueva información (activo o teórico) y la segunda dimensión que profundiza en la forma de cómo se procesa la nue- va información (pragmático o reflexivo). El estilo de aprendizaje está relacionado con el rendimiento académico y con la decisión de escoger una especialidad en estudiantes de odontología, de ahí la importancia de conocer su estilo de aprendizaje como estudiante de odontología. El Objetivo de este estudio fue determinar la distribución de frecuencia de los estilos de aprendizaje predominantes en los estudiantes de primer y segundo año de la facultad de estomatología de la Universidad Peruana Cayetano Heredia. Como instrumento se utilizó el test Honey-Alonso CHAEA, que discrimina la predominancia de un estilo de aprendizaje de dos dimensiones, en una dimensión entre reflexivo o activo y en otra dimensión entre teórico o pragmático. Se encontró como resultados la distribución de frecuencia de los estilos de aprendizaje en la población estudiada se dio de la siguiente manera; Reflexivo teórico $29 \%$; Pragmático teórico $18 \%$; Pragmático activo 16\%; Activo reflexivo 13\%; solo reflexivo $8 \%$; solo teórico $8 \%$; solo activo $5 \%$ y solo pragmático 3\%. Llegando a la conclusión que el estilo predominante Reflexivo y Teórico implica, procedimientos metodológicos, lógicos, críticos y estructurados al momento de percibir nueva información y ponderación, búsqueda cuidadosa detallista de información y razonamiento crítico al momento de procesar el nuevo conocimiento, es decir los estudian- 
tes evaluados en su mayoría necesitan entender antes de memorizar algún contenido, de ahí la importancia del factor docente en el proceso de enseñanza aprendizaje.

\section{Higiene oral en madres de niños menores de 5 años de edad del AA. HH. EI Golfo de Ventanilla de la Ciudad Pachacutec - Callao en el año 2011.}

Ostos $\mathrm{B}{ }^{1}$, Blaise $\mathrm{F}^{1}$, Remigio $\mathrm{R}^{1}$, Vargas $\mathrm{Y}^{1}$, LeónManco R ${ }^{2}$

${ }^{1}$ Alumno de Primer Año de la Facultad de Estomatología Universidad Peruana Cayetano Heredia. Lima, Perú.

${ }^{2}$ Facultad de Estomatología Universidad Peruana Cayetano Heredia. Lima, Perú.

La presente investigación fue transversal, descriptivo, observacional y cuantitativo; aborda la problemática de la higiene oral como medida preventiva para la presencia de otras enfermedades y como su control es necesaria para garantizar una adecuada salud bucal. El objetivo fue determinar el Índice de Higiene Oral en madres de niños menores 5 años de edad del AA. HH. El Golfo de Ventanilla de la Ciudad de Pachacútec, del Distrito de Ventanilla-Callao en el año 2011. La muestra estuvo conformada por la totalidad de las madres con niños menores de 5 años de edad, del AA. HH. El Golfo de Ventanilla. La variable seleccionada para medir la higiene oral fue el Índice de Higiene Oral Simplificado (IHO-S). Los resultados se analizaron a través de la frecuencia relativa y absoluta de la variable usando el software Microsoft Excel. En los resultados se encontró que la población presentó una baja prevalencia en la condición bueno de la IHO-S con un 6,3 $\%$, luego le siguió la condición malo con un $12,5 \%$ y por último, la condición regular, que presentó una alta prevalencia con $81,3 \%$. El promedio de IHO-S de las madres fue 2,25, siendo una condición regular; por lo cual podemos llegar a la conclusión que las madres de niños menores de 5 años de edad del AA. HH. El Golfo de Ventanilla de la Ciudad de Pachacútec, del Distrito de Ventanilla-Callao tienen mayoritariamente una condición de higiene oral regular en el año 2011.

Perfil de conocimientos y actitudes sobre salud oral en madres de infantes de 0 a 5 años de edad de la ciudad de Pachacútec, Distrito de Ventanilla, Provincia del Callao, Departamento de Lima en el año 2011.
Parra N ${ }^{1}$, Morales S ${ }^{1}$, Quiquia $\mathrm{M}^{1}$, Camacho R ${ }^{1}$, Hadad $\mathrm{N}^{2}$

${ }^{1}$ Alumno de Primer Año de la Facultad de Estomatología Universidad Peruana Cayetano Heredia. Lima, Perú.

${ }^{2}$ Facultad de Estomatología Universidad Peruana Cayetano Heredia. Lima, Perú.

En la actualidad la Estomatología está orientada a la prevención de las enfermedades más comunes que afectan a la salud bucal como la gingivitis, las enfermedades periodontales, la caries dental, entre otros. La prevención temprana es la mejor alternativa de solución para evitar las patologías bucales. Por ello el cuidado de la salud bucal se debe tener desde los primeros años de vida con la debida supervisión de los padres, ya que la familia es la responsable de instruir a los menores las buenas prácticas de higiene oral. Así el menor estará adquiriendo más conocimientos $\mathrm{y}$ actitudes sobre su salud bucal para que en un futuro éste tenga adecuados hábitos y mantenga una buena salud. Por ello, el presente estudio busca determinar los conocimientos y actitudes de los padres para posteriormente elaborar estrategias que mejoren dichos aspectos. Lo más complejo de todo es que la solución está en manos de todos, sobre todo en la enseñanza de padres a hijos. El objetivo de este estudio fue determinar los conocimientos y actitudes sobre salud oral en madres de infantes de 0 a 5 años de edad de la ciudad de Pachacútec, distrito de Ventanilla, provincia del Callao, departamento de Lima del año 2011. La presente investigación de tipo transversal, descriptivo, observacional y con enfoque cuantitativo tuvo como población las madres de infantes de 0 a 5 años de edad de Pachacútec, distrito de Ventanilla, provincia del Callao, departamento de Lima en el año 2011 por lo que la muestra estuvo conformada por 20 madres de estos infantes entre 0 a 5 años de edad. Se utilizó el Cuestionario para evaluar los Conocimientos y las Actitudes de Padres/cuidadores de niños menores de 5 años. Dicho instrumento constó de 39 preguntas de las cuales 25 fueron de conocimientos y 14 de actitudes. Antes de ser aplicado para el presente estudio ha sido revalidado por el Departamento Académico de Odontología Social de la Facultad de Estomatología Roberto Beltrán de la Universidad Peruana Cayetano Heredia. Los resultados obtenidos según la presente investigación fueron los siguientes: El 100\% de las madres de infantes de 0 a 5 años de edad evidencia- 
ron un nivel escaso de conocimientos respecto a salud oral y el $70 \%$ de las madres de infantes de 0 a 5 años de edad tuvieron un nivel aceptable de actitudes en salud oral, el $20 \%$ de ellas presentó un nivel bueno y el $10 \%$ mostró un nivel bajo. Se concluye lo siguiente que el nivel de conocimientos sobre salud oral de todas las madres participantes en el estudio resultó escaso, observándose que ninguna de ellas llegó a obtener un nivel aceptable o bueno, la mayoría de las madres obtuvieron un nivel aceptable de actitudes en salud oral, seguido a ello una proporción más reducida de madres mostraron un nivel bueno y la minoría de ellas resultaron con un nivel malo de actitudes con respecto a salud bucal.

Tracción de muestras de diferentes tipos de resina hasta su fracturación para evaluar su resistencia a la tensión.

Pimentel $\mathrm{T}^{1}$, De armas A ${ }^{1}$, Rodríguez $\mathrm{K}^{1}$, Romero B ${ }^{1}$, Rosales $\mathrm{W}^{1}$, Villafuerte M 1 , López $\mathrm{M}^{2}$, Castillo D ${ }^{2}$, Sisniegas $\mathrm{G}^{3}$

${ }^{1}$ Alumno de Primer Año de la Facultad de Estomatología Universidad Peruana Cayetano Heredia. Lima, Perú.

${ }^{2}$ Facultad de Estomatología Universidad Peruana Cayetano Heredia. Lima, Perú.

${ }^{3}$ Facultad de Ciencias y Filosofía Universidad Peruana Cayetano Heredia. Lima, Perú.

Las resinas se han ido difundiendo progresivamente desde el s. XIX coexistiendo e incluso sustituyendo a otros materiales en la práctica estomatológica, como las amalgamas en los trabajos de obturación y en la manufactura de prótesis dentales, y a la vez han ido perfeccionándose su practicidad y eficiencia estructural, facilitándose en el transcurso su manipulación y aplicación, tornándolas, así, en una elección natural en la práctica odontológica. Ya que su uso estomatológico está muy relacionado con eventos de naturaleza mecánica como soportar tensiones en el proceso masticatorio se ha hecho importante obtener las características de sus propiedades físicas tales como la adhesividad y la resistencia a las diversas tensiones a las que probablemente será sometido, constituyendo este último el motivo de este trabajo. La presente investigación, tipo experimental de corte transversal, tuvo como objetivo desarrollar un módulo que efectúe la fracturación de muestras confeccionadas con diversos tipos de resina permitiéndonos su evaluación y comparación. Se fabricó un módulo práctico que permitió la fracturación de las muestras mediante la combinación de dispositivos relativamente económicos y de fácil adquisición. Dicho módulo consta de cuatro partes principales: el tractor, el medidor, el portamuestras y el sistema perimétrico de soporte; mediante la utilización de este instrumento se aplicó una fuerza de tensión de dos resinas de uso comercial. Aunque, estadísticamente, todos los datos tienen una dispersión considerable permitieron la evaluación y comparación de dos tipos de resina, determinándose que la resina (LLIS) resistió mejor que la $(3 \mathrm{M})$, pero dada la menor dispersión de datos en la (3M) sugiere una mejor confiabilidad estructural. La experiencia llevó a la conclusión que la construcción de instrumentos para evaluar la tensión de un material es posible, permitiéndonos analizar y caracterizar los materiales dentales, que en este caso fueron resinas. Teniendo en consideración que el presente estudio, de naturaleza piloto y exploratoria, tuvo limitaciones ya que solo se evaluaron dos muestras por grupo de estudio y que no fueron sometidos a una estandarización al momento de su fabricación.

Identificación de los queratoquistes odontogénicos del maxilar inferior mediante imágenes radiográficas en pacientes de 5 a 75 años diagnosticados entre 1990 al 2010 en la clínica dental de la Universidad Peruana Cayetano Heredia. Lima, Perú.

Álvarez V ${ }^{1}$, Arteaga A ${ }^{1}$, Betancourt $\mathrm{M}^{1}$, Galarza S ${ }^{1}$, Mendoza $\mathrm{Y}^{1}$, Ricaldi ${ }^{2}$, Altamirano $\mathrm{A}^{3}$

${ }^{1}$ Alumno de Primer Año de la Facultad de Estomatología Universidad Peruana Cayetano Heredia. Lima, Perú.

${ }^{2}$ Facultad de Estomatología Universidad Peruana Cayetano Heredia. Lima, Perú.

${ }^{3}$ Facultad de Ciencias y Filosofía Universidad Peruana Cayetano Heredia. Lima, Perú.

Los Queratoquistes Odontogénicos (QQO) son un tipo de quistes benignos, que fueron inicialmente descritos por Phillips en 1956; son lesiones que generalmente ocurren en el área maxilo-mandibular, los cuales se originan de restos de la lámina dental o de remanentes de la capa basal de la mucosa oral presentes en el maxilar superior y la mandíbula. Para reportar la localización de la lesión se han utilizado varios parámetros para determinar la ubicación de la lesión, 
esto puede realizarse mediante radiografías panorámicas, tomografías u otros exámenes auxiliares; sin embargo se requiere de conocimiento para identificarlos y reconocer su extensión. El procesamiento de imágenes radiográficas con el software MATLAB, facilitará la identificación de las zonas afectadas con mayor detalle mediante el uso de filtros. Finalmente esto nos ayudará a la planificación del tratamiento más adecuado. El objetivo de la investigación fue identificar los Queratoquistes Odontogénicos mediante imágenes radiográficas analizadas por un software de procesamiento de imágenes (Matlab) para el diagnóstico de lesiones quísticas en pacientes de 6 a 75 años atendidos en la Clínica Estomatológica UPCH durante 1990-2010. El presente estudio es no experimental, de tipo transversal ya que se evaluarán radiografías panorámicas de diagnóstico. Así mismo es del tipo descriptivo, no probabilístico, debido a la selección de casos de pacientes ya diagnosticados con QQOs. La muestra fue tomada de las radiografías panorámicas entre 1990 y 2010 a pacientes entre los 5 y 75 con el diagnostico de QQOS en la Clínica Estomatológica Central de la Facultad de Estomatología “Roberto Beltrán”.Se realizó la selección de radiografías de pacientes diagnosticados con QQOS en el área de radiología oral en la Clínica Estomatológica central de la facultad de Estomatología Roberto Beltrán de la Universidad Peruana Cayetano Heredia durante los años 1990 y 2010, se procedió a realizar el procesamiento de imágenes con el programa Matlab versión 2010 para la identificación de QQOs. Las imágenes estudiadas tienen una secuencia de análisis, se empleó la herramienta interactiva del Matlab "imtool" para procesar imágenes; esta herramienta permitió seleccionar las áreas de estudio de manera sencilla. Luego de segmentar la imagen a estudiar se determinó el contorno de la lesión quística mediante un programa. Ubicada la región de interés, se graficaron las densidades en las escalas de grises de las imágenes segmentadas. Dentro de los resultados encontramos que de los 11 casos seleccionados, $6(54,54 \%)$ correspondieron a mujeres mientras que los $5(45,46 \%)$ restantes pertenecían a hombres. El rango de edad estuvo entre 5 años y 75 años. En conclusión se puede mencionar que los casos identificados con QQOs, fue de mayor prevalencia en el género masculino (54,5\%), en el femenino, es menos de la mitad (45,5\%). Los QQO se muestran con mayor frecuencia en varones de la segunda y tercera década de la vida.Los QQOs muestran una tendencia a recidivar, debido a sus particularidades histológicas y a su actividad proliferativa intensa de su epite- lio. De acuerdo a las investigaciones realizadas, los QQOs pueden ser asintomáticos, así como también pueden llegar a destruir el hueso mandibular o causar desórdenes en las piezas dentarias. De los 11 casos identificados con QQOs, se pudo observar una mayor prevalencia en la zona del maxilar inferior a comparación con la zona del maxilar superior. Se lograron obtener estos resultados mediante la segmentación de la imagen, el mejoramiento del contraste y las tonalidades de la escala de grises, en los histogramas de las imágenes radiográficas. El uso de un procesamiento de imágenes ayudo a identificar los posibles QQOs y brindó una nueva forma de analizar este tipo de casos.

\section{Evaluación in vitro de la acidez de cervezas más consumidas en el perú y su efecto sobre el esmalte dental.}

Cárdenas $\mathrm{C}^{1}$, Montenegro $\mathrm{C}^{1}$, Pérez $\mathrm{B}{ }^{1}$, Velásquez $\mathrm{G}^{1}$, De la Cruz $\mathrm{S}^{1}$, Huayta $\mathrm{K}^{1}$, Cabrera $\mathrm{A}^{2}$, Peralta $\mathrm{J}^{3}$

${ }^{1}$ Alumno de Primer Año de la Facultad de Estomatología Universidad Peruana Cayetano Heredia. Lima, Perú.

${ }^{2}$ Facultad de Estomatología Universidad Peruana Cayetano Heredia. Lima, Perú.

${ }^{3}$ Facultad de Ciencias y Filosofía Universidad Peruana Cayetano Heredia. Lima, Perú.

El esmalte dental es un tejido formado principalmente por hidroxiapatita y proteínas (en muy baja proporción). A pesar de ser el tejido más duro del cuerpo humano, este es susceptible a ser desgastado (desmineralizado), causando así una erosión dental, que es la pérdida progresiva e irreversible del tejido dental por un proceso químico que no involucra acción bacteriana. Muchos de los ácidos presentes en algunas bebidas y frutas son los causantes de la desmineralización de la matriz inorgánica dental. Se ha demostrado que cuando el esmalte está expuesto a sustancias ácidas cuyos valores de $\mathrm{pH}$ sean menores a 4,5 - 5,5, la superficie dental es destruida debido a la disolución de la hidroxiapatita del esmalte, con la correspondiente liberación iones calcio. El incremento en el consumo de bebidas son factores de estilo de vida considerados muy importantes con respecto al desarrollo de la erosión dental. En el Perú, el consumo de bebidas alcohólicas es masivo y alto, lo cual podría ser un riesgo para la salud bucal de la población. En su composición la cerveza presenta ácidos orgánicos (ácido láctico), an- 
hídrido carbónico, etanol, azucares, dextrinas, glicerina, proteínas, sales minerales, sustancias aromáticas, entre otros. Muchos de estos compuestos tienen propiedades ácidas que podrían destruir la superficie dental o tal vez terminar con la fractura dentaria. El objetivo del presente estudio fue evaluar, in vitro, el efecto erosivo que causa la acidez de cervezas sobre la superficie del esmalte dental, mediante la determinación de calcio por espectroscopia de absorción atómica. Se emplearon piezas dentarias sanas, extraídos por motivos ortodónticos, libres de caries, sin malformaciones y que no presentaron grietas o líneas de fractura, las cuales fueron recolectas en la Clínica Cayetano Heredia. Las piezas dentarias fueron lavadas para remover los residuos de tejidos periodontal. Todos los dientes se almacenaron en suero fisiológico para evitar su deshidratación. Cada pieza dentaria fue dividida en dos partes empleando un disco de corte siguiendo un eje longitudinal, una de estas mitades fue el grupo control. Seguidamente las piezas dentarias fueron expuestas a la acción de las bebidas alcohólicas $(50 \mathrm{ml})$ durante dos días.Se midieron el pH de cervezas de mayor preferencia en el Perú: Pilsen, Brahma, Cristal y Cuzqueña. Asimismo, se determino la acidez total (porcentaje de ácido láctico) de las muestras de cerveza, mediante titulación potenciométrica con solución de $\mathrm{NaOH}$ 0,1 M. El efecto erosivo se evaluó midiendo la concentración de calcio en las muestras de cervezas, antes y después de ser colocadas en contacto con las piezas dentarias. En la primera parte de este estudio se midió el pH de cervezas de mayor preferencia en el Perú y se determinó la acidez total en función del porcentaje de ácido láctico. Se observa que todas las muestras de cerveza presentan carácter ácido, cuyos valores de $\mathrm{pH}$ varían de 4,32 a 4,63. La cerveza Brahma presentó un $\mathrm{pH}$ ligeramente más ácido en comparación con las otras muestras. Las cervezas Pilsen, Cuzqueña y Brahma presentaron similar porcentaje de ácido láctico, en comparación a la muestra de Cristal que presenta menor porcentaje. De acuerdo a la liberación de calcio por cada gramo de diente se observó mayor cantidad a la Pilsen con $39.56 \mathrm{mg} / \mathrm{L}$. Se concluyó que la erosión dental producida por el consumo de cerveza está relacionada con el $\mathrm{pH}$ ácido de estas; todas las cervezas presentaron $\mathrm{pH}$ menores a 4,6. Estos valores son menores al $\mathrm{pH}$ crítico de la hidroxiapatita, $\mathrm{Ca}_{10}(\mathrm{PO} 4)_{6}(\mathrm{OH})_{2},(\mathrm{pH}=5,5)$; el mismo que favorece la desmineralización de la superficie del esmalte dental. La cerveza Pilsen fue la que presentó mayor efecto erosivo en comparación con la cerveza Brahma. Este resultado está relacionado con la mayor acidez total $(0,19$
\% de ácido láctico) presente en la cerveza Pilsen.

Bacterias microaerofilas presentes en la saliva de pacientes portadores y no portadores de prótesis que asisten a la Clínica Estomatológica de la Universidad Peruana Cayetano Heredia. Octubre 2011.

Iannacone $\mathrm{R}^{1}$, Jo E ${ }^{1}$, López X ${ }^{1}$, López A ${ }^{1}$, Mere ${ }^{1}$, Ramírez $\mathrm{P}^{1}$, Velásquez $\mathrm{Z}^{2}$, Castillo $\mathrm{D}^{2}$, Maurtua $\mathrm{D}^{3}$.

${ }^{1}$ Alumno de Primer Año de la Facultad de Estomatología Universidad Peruana Cayetano Heredia. Lima, Perú.

${ }^{2}$ Facultad de Estomatología Universidad Peruana Cayetano Heredia. Lima, Perú.

${ }^{3}$ Facultad de Ciencias y Filosofía Universidad Peruana Cayetano Heredia. Lima, Perú.

El uso de prótesis dentales se ha vuelto muy común en la población, tanto adulta como jóvenes y esto independientemente del tipo de material. En los diferentes tipos de prótesis, se tiende a acumular placa bacteriana, principalmente en las zonas rugosas, porosas y en aquellas de muchos años de uso, se ha demostrado que los acrílicos utilizados en odontología tienen mayor capacidad de adsorción de amilasa y albumina favoreciendo la adhesión de la placa bacteriana subprotésica y penetrando los microorganismos dentro de la resina. De esta forma la prótesis constituye un reservorio de microorganismos favoreciendo la presencia de microorganismos microaerofilos, quienes solo requieren $10 \%$ de $\mathrm{CO}_{2}$ y una pequeña cantidad de $\mathrm{O}_{2}$ para crecer. Los Streptococcus y Lactobacillus son las bacterias que más prevalecen en saliva y son microaerofilas. Sin embargo se hace necesario conocer el número de bacterias (UFC) formadoras de colonias que están presentes en saliva de pacientes portadores y no portadores de prótesis. El presente estudio tiene una importancia social ya que al conocer, cuales microorganismos y la cantidad de bacterias microaerofilas están en la saliva de pacientes portador y no portadores de prótesis, se podrá orientar a los individuos a realizar una higiene adecuada para disminuir el riesgo de adquirir alguna enfermedad. El objetivo de la presente investigación fue determinar la presencia de bacterias microaerofilas presentes en saliva de pacientes portadores y no portadores de prótesis que acuden a la clínica odontológica de la Universidad Peruana Cayetano Heredia (UPCH). Para 
el presente estudio se tomaron 10 muestras de saliva, 5 con prótesis y 5 sin prótesis en vasos estériles, luego fueron transportados al laboratorio a $4^{\circ} \mathrm{C}$ hasta su procesamiento. En el laboratorio de Bacteriología del Departamento de Ciencias Celulares y moleculares de la Facultad de ciencias y Filosofía de la UPCH se realizaron diluciones seriadas a partir de $10^{-1}$ hasta $10^{-6} \mathrm{y}$ se sembró 0,1 mL de las 2 últimas diluciones en Agar MRS y en Agar Mitis salivarus (AMS). Luego fueron colocados en sistema de microaerofilia por 24 horas a $37{ }^{\circ} \mathrm{C}$ para AMS y el Agar MRS se mantuvo a $37^{\circ} \mathrm{C}$ por 48 horas. Transcurrido el tiempo se realizaron los recuentos correspondientes, tinción de Gram, Catalasa y oxidasa de todas las colonias sospechosas para la identificación de Lactobacillus sp y Streptococcus sp. De las 10 muestras de saliva, el 20\% se identifico Lactobacillus sp y el $80 \%$ fueron Streptococcus sp. De las 5 muestras de saliva de pacientes con prótesis solo se identificaron Streptocucus sp con recuentos de $35 \times 10^{7}$ a $49 \times 10^{7} \mathrm{ufc} / \mathrm{mL}$ de saliva. De las 5 muestras sin prótesis solo se aisló Streptocucus sp con recuentos de $16 \mathrm{x}$ $10^{7}$ a $1056 \times 10^{7} \mathrm{ufc} / \mathrm{mL}$ de saliva y Lactobacillus con recuentos de $136 \times 10^{7}$ a $336 \times 10^{7} \mathrm{ufc} / \mathrm{mL}$ de saliva. Una sola persona mostro presencia de Streptococcus con un recuento demasiado $1052 \times 10^{7} \mathrm{ufc} / \mathrm{mL}$. Los resultados obtenidos demuestran que todas las personas portadoras de prótesis solo presentaron Streptococcus $s p$ y las personas sin prótesis presentaron Streptococcus sp y Lactobacillus sp. 